\title{
Cardiovascular tests of autonomic function and sympathetic skin responses in patients with major depression
}

\author{
Salvador M Guinjoan, Juan L Bernabó, Daniel P Cardinali
}

\begin{abstract}
To assess the function of the autonomic nervous system in major depression, a series of cardiovascular tests, together with the recording of sympathetic skin response, were performed in 18 depressed patients (melancholic type, DSM-III-R criteria) and in 18 healthy control subjects. Depressed patients showed significantly poorer performance in Valsalva's, deep breathing, and lying to standing manoeuvres than controls, indicating an impairment of parasympathetic function. Depressed patients developed a significantly larger sympathetic skin response than controls during the lying to standing and hand grip manoeuvres, whereas cardiovascular sympathetic performance (as assessed by the responses to hand grip, cold, mental arithmetic, explosive sound, or hyperventilation) was similar in both groups. The results are compatible with the view that a diminished parasympathetic reactivity, and presumably an increased sympathetic reactivity, occur in patients with major depression.
\end{abstract}

(F Neurol Neurosurg Psychiatry 1995;58:299-302)

Keywords: depression; sympathetic nervous system parasympathetic nervous system; electrodermal response

The relation between depression and disturbances of autonomic regulation has been recognised for a long time. For example, Kraepelin reported increased resting blood pressure values in depressed patients, as well as the well known disturbances of body weight, sleep, and sexual activity. ${ }^{1}$ Kraepelin also stated that this abnormality was related to the severity of the disease. ${ }^{1}$ The topic received relatively little attention, however, ${ }^{2-4}$ until the recent interest triggered by the recognition that depressed patients are at an augmented risk for cardiovascular diseases. ${ }^{2567}$ For example, a decreased heart rate variability, presumably a consequence of an increased sympathetic input and a decreased parasympathetic input to the heart, is a predictor of mortality after myocardial infarction ${ }^{7}$ and sudden cardiac death. ${ }^{8}$ The same autonomic disturbances were found to be responsible for the increased cardiovascular risk in patients with depression, ${ }^{256}$ cardiovascular patients tending to have significant depression. ${ }^{9}$ Also abnormal neuroendocrine responses to centrally acting autonomic drugs - for example, clonidinewere identified as trait markers for endogenous. depression, suggesting an abnormal central autonomic function in depressed patients. ${ }^{10}$

In a recent study we reported an increased sympathetic reactivity in patients with affective disorders, which was related to the degree of psychopathology. ${ }^{4}$ This finding prompted us to examine whether autonomic regulation, as estimated by non-invasive cardiovascular tests of autonomic function and sympathetic skin responses, was altered in the course of episodes of major depression. Autonomic function assessment included determination of the SD of R-R intervals, expiration:inspiration (E:I) ratio, Valsalva ratio, 30:15 ratio, and pressor responses to hand grip, cold, mental arithmetic, explosive sound, or hyperventilation, together with the simultaneous recording of sympathetic skin response. Similar tests of autonomic function have been used for diagnostic purposes in various conditions, including diabetes, amyloidosis, alcoholism, acute porphyria, and primary disorders of the autonomic nervous system. ${ }^{11} 12$

\section{Patients and methods \\ PATIENTS}

Eighteen patients (nine men, nine women) with a diagnosis of major depression (melancholic type) and 18 control subjects (six women, 12 men) were studied. All participants gave informed consent. The mean (SD) age of depressed patients was 44 (12) years, and that of controls was 40 (13) years. Patients met DSM-III-R criteria of major depression, melancholic type ${ }^{13}$ and did not have any current (or history of) other psychiatric illness, apart from nicotine use in one of them, a man who smoked up to 25 cigarettes a day. Mean time from the beginning of the current major depression episode, as estimated from the clinical recordings, was 1.5 (1) months. Control subjects had no current (or history of) psychiatric illness, except for a nicotine use in two men, who smoked 15-25 cigarettes a day. Neither control nor depressed subjects had any history of cardiovascular, respiratory, endocrinological, neurological, or other physical illnesses (including diabetes mellitus and alcoholism). Chagas' disease was ruled out by serological criteria.

Overall severity of psychiatric disease was assessed by the psychopathology index of the Minnesota multiphasic personality inventory 
(MMPI) (the average of scores obtained in the clinically relevant scales). ${ }^{14}$ The mean psychopathology index score in depressed patients was 78 (SD 8) and in normal controls it was $60(6)(P<0.0001$, Student's $t$ test $)$. Scores for the depression scale in MMPI in depressed patients and control subjects were $93(18)$ and $65(23)$ respectively $(P=0.0003$, Student's $t$ test).

The subjects had not taken any medication for at least 10 days before the study, and were asked to avoid beverages containing caffeine during a 12 hour period before the study. Smokers agreed to avoid cigarettes from three hours before the study, as previously recommended. ${ }^{15}$ Before the wash out period, three patients had been taking lorazepam $(4 \mathrm{mg} /$ day) and three patients had been taking bromazepam on an irregular basis $(0.5$ to $3 \mathrm{mg} /$ day). One of the patients on lorazepam had also taken levomepromazine ( $25 \mathrm{mg} /$ day) and tranylcypromine (25 mg/day). Medications with anticholinergic side effects such as levomepromazine, may have mild effects on cardiovagal measures, and moderate to profound effects on sudorimotor activity tests, ${ }^{16}$ a wash out period of 48 hours being recommended for these types of drugs. ${ }^{17}$

AUTONOMIC NERVOUS SYSTEM ASSESSMENT All tests were performed between 0900 and 1200 , at least two hours after a light breakfast, and with the subjects in a supine position.

\section{Cardiovascular tests of autonomic function}

An analog electrocardiograph and an automatic blood pressure manometer were used for scoring the standard tests of autonomic function. All tests were applied in a random sequence in the same session, which lasted about 90 minutes. The expiration:inspiration (E:I) ratio was calculated as the average of the quotients between the longest R-R interval during expiration and the shortest $\mathbf{R}-\mathbf{R}$ interval during inspiration for six consecutive respiratory cycles at a rate of $0 \cdot 1 \mathrm{~Hz} .{ }^{18}$

The Valsalva's ratio was calculated as the quotient between the longest $R-R$ interval during the poststrain phase and the shortest $R-R$ interval during the strain phase, the last being a 20 second period during which the subject blew on to an open loop manometer to sustain a pressure of $5.3 \mathrm{kPa}(40 \mathrm{~mm} \mathrm{Hg})$. Three consecutive Valsalva's manoeuvres were performed, and the highest Valsalva's ratio was taken for computation. ${ }^{19}$

The 30:15 ratio in a lying to standing manoeuvre was calculated as the quotient between the longest R-R interval at or about the 30th beat and the shortest $R-R$ interval at or about the 15 th beat after standing. ${ }^{20}$

Diastolic blood pressure response to isometric exercise was calculated as the difference between diastolic blood pressure after one minute hand grip at $30 \%$ of maximal effort and diastolic blood pressure at rest, which is a modification of the technique described by Ewing et al. ${ }^{21}$

The response to cold was recorded as the difference between systolic blood pressure, diastolic blood pressure, and heart rate after a 60 second immersion of the hand in water at $4^{\circ} \mathrm{C}$ and the same values obtained at rest. ${ }^{22}$ Responses to performance of mental arithmetic (successive subtraction of 7 from 700) for one minute ${ }^{23}$ and to hyperventilation for 30 seconds were evaluated in a similar way to the cold response. The explosive sound was a $60 \mathrm{~dB}$ intense, six second long tumble sound recorded on a tape and delivered through earphones. ${ }^{4}$

Additionally, the SD of 150 R-R interval epochs obtained during quiet breathing was calculated as an index of heart rate variability. ${ }^{24}$

\section{Sympathetic skin responses}

Sympathetic skin responses during the tests described were recorded and stored as previously reported. ${ }^{425}$ To accomplish this, standard surface electromyograph disc electrodes (10 mm diameter) were applied with conducting paste to the palm and to the dorsum of the hand, with a reference electrode on the forearm. Skin potential changes during and between the tests were amplified and digitised by an Autogenic System Inc TM 3400 electrodermograph and the data were processed with a microcomputer. The amplitude of sympathetic skin response in epochs of one minute (stimulus beginning at the sixth second) was computed for analysis.

\section{STATISTICS}

Two sample, independent group Student's $t$ tests were employed for comparison of results. Significant differences between groups were assumed at an $\alpha=0.05$.

\section{Results}

The table summarises the results of the different autonomic tests performed in depressed patients and controls. In view of the exclusion criteria employed, all those participating in the study performed normally in autonomic tests according to the values reported in the literature to assess autonomic damage. ${ }^{2026}$

Control subjects attained significantly higher Valsalva's ratios than the depressed patients $(P=0.027$; table). The same was true for $E: I(P=0.039)$ and $30: 15$ ( $P=$ 0.018 ) ratios. Measurements of $R-R$ interval variability, diastolic blood pressure response to hand grip, cold pressor test, and cardiovascular responses to mental arithmetic, explosive sound, and hyperventilation, yielded statistically similar values in both groups (table).

The table also shows the amplitude of the sympathetic skin response recorded during the cardiovascular tests in the depressed patients and control subjects. The amplitude of the sympathetic skin response elicited by lying to standing and hand grip manoeuvres in depressed patients were significantly larger than those found in control subjects. 
Cardiovascular tests of autonomic function and evoked sympathetic skin responses in 18 patients with major depression and 18 control subjects

\begin{tabular}{|c|c|c|c|}
\hline & Control $(n=18)$ & Depression $(n=18)$ & $P$ value \\
\hline $\begin{array}{l}\text { Resting values: } \\
\text { Systolic blood pressure (mm Hg) } \\
\text { Diastolic blood pressure }(\mathrm{mm} \mathrm{Hg}) \\
\text { Heart rate (beats/min) } \\
\text { SSR (mV) }\end{array}$ & $\begin{array}{r}118(16) \\
74(12) \\
70(10) \\
2(2)\end{array}$ & $\begin{array}{c}120(17) \\
76(12) \\
69(6) \\
3(2)\end{array}$ & $\begin{array}{l}\text { NS } \\
\text { NS } \\
\text { NS } \\
\text { NS }\end{array}$ \\
\hline $\begin{array}{l}\text { Evoked changes: } \\
\text { Valsalva manoeuvre: } \\
\text { Heart rate ratio } \\
\text { SSR (mV) }\end{array}$ & $\begin{array}{l}1 \cdot 85(0.46) \\
8(6)\end{array}$ & $\begin{array}{l}1 \cdot 58(0.34) \\
8(5)\end{array}$ & $\begin{array}{l}0.027 \\
\text { NS }\end{array}$ \\
\hline $\begin{array}{l}\text { Lying to standing: } \\
30: 15 \text { ratio } \\
\text { SSR (mV) }\end{array}$ & $\begin{array}{l}1 \cdot 49(0 \cdot 24) \\
7(4)\end{array}$ & $\begin{array}{l}1.33(0 \cdot 19) \\
15(13)\end{array}$ & $\begin{array}{l}0.035 \\
0.027\end{array}$ \\
\hline $\begin{array}{l}\text { Deep breathing: } \\
\text { E:I ratio } \\
\text { SSR }(\mathrm{mV})\end{array}$ & $\begin{array}{l}1 \cdot 35(0 \cdot 17) \\
5(5)\end{array}$ & $\begin{array}{l}1 \cdot 26(0 \cdot 12) \\
5(2)\end{array}$ & $\begin{array}{l}0.039 \\
\text { NS }\end{array}$ \\
\hline $\begin{array}{l}\text { Hyperventilation: } \\
\text { Systolic blood pressure (mm Hg) } \\
\text { Diastolic blood pressure (mm Hg) } \\
\text { Heart rate (beats/min) } \\
\text { SSR (mV) }\end{array}$ & $\begin{array}{l}0(8) \\
0(6) \\
6(9) \\
9(6)\end{array}$ & $\begin{array}{l}0(5) \\
0(4) \\
5(7) \\
9(5)\end{array}$ & $\begin{array}{l}\text { NS } \\
\text { NS } \\
\text { NS } \\
\text { NS }\end{array}$ \\
\hline $\begin{array}{l}\text { Handgrip: } \\
\text { Diastolic blood pressure (mm Hg) } \\
\text { SSR (mV) }\end{array}$ & $\begin{array}{l}9(8) \\
4(3)\end{array}$ & $\begin{array}{l}8(6) \\
8(7)\end{array}$ & $\begin{array}{l}\text { NS } \\
0.047\end{array}$ \\
\hline $\begin{array}{l}\text { Cold pressor test: } \\
\text { Systolic blood pressure (mm Hg) } \\
\text { Diastolic blood pressure (mm Hg) } \\
\text { Heart rate (beats } / \mathrm{min}) \\
\text { SSR (mV) }\end{array}$ & $\begin{array}{l}7(16) \\
8(5) \\
-4(8) \\
4(2)\end{array}$ & $\begin{array}{r}12(10) \\
6(5) \\
-2(5) \\
6(5)\end{array}$ & $\begin{array}{l}\text { NS } \\
\text { NS } \\
\text { NS } \\
\text { NS }\end{array}$ \\
\hline $\begin{array}{l}\text { Mental arithmetic: } \\
\text { Systolic blood pressure (mm Hg) } \\
\text { Diastolic blood pressure (mm Hg) } \\
\text { Heart rate (beats/min) } \\
\text { SSR (mV) }\end{array}$ & $\begin{array}{c}11(9) \\
8(9) \\
10(17) \\
5(3)\end{array}$ & $\begin{array}{r}10(9) \\
6(9) \\
8(8) \\
6(3)\end{array}$ & $\begin{array}{l}\text { NS } \\
\text { NS } \\
\text { NS } \\
\text { NS }\end{array}$ \\
\hline $\begin{array}{l}\text { Explosive sound: } \\
\text { Systolic blood pressure (mm Hg) } \\
\text { Diastolic blood pressure (mm Hg) } \\
\text { Heart rate (beats/min) } \\
\text { SSR (mV) }\end{array}$ & $\begin{array}{r}-4(3) \\
-2(3) \\
0(3) \\
5(4)\end{array}$ & $\begin{array}{r}-1(6) \\
-2(4) \\
1(4) \\
4(3)\end{array}$ & $\begin{array}{l}\text { NS } \\
\text { NS } \\
\text { NS } \\
\text { NS }\end{array}$ \\
\hline
\end{tabular}

Results are means (SD). Actual changes in systolic blood pressure, diastolic blood pressure and heart rate are shown. Sympathetic skin responses (SSR) were obtained during cardiovascular tests. the Valsalva's, lying to standing (30:15 ratio), and deep respiration at $0 \cdot 1 \mathrm{~Hz}$ (E:I ratio) manoeuvres are commonly employed to assess the damage of either the afferent or the efferent limbs of cardiovascular reflexes. ${ }^{11} 1820$ Although both sympathetic and parasympathetic fibres participate in the changes of $R-R$ interval after these procedures, all of them have been assumed to assess mainly the integrity of the parasympathetic fibres participating in the autonomic control of the heart. Thus an impaired Valsalva's ratio indicated parasympathetic damage in diseases such as diabetes mellitus, ${ }^{37}$ alcoholism, ${ }^{30}$ and acute porphyria. ${ }^{31} \mathrm{E}: \mathrm{I}$ and $30: 15$ ratios have also been considered indicative of integrity of parasympathetic fibres, mainly in diabetes. ${ }^{1820}$ Our present results, of smaller Valsalva's, E:I, and 30:15 ratios in depressed patients are thus in agreement with the data supporting an increased sympathetic activity or decreased parasympathetic activity in such patients, as shown by an increased heart rate, ${ }^{3383940}$ a decreased high frequency variability of heart rate, ${ }^{41}$ and increased heart rate in response to standing. ${ }^{42}$

In the present study, no differences in resting heart rate variation, as measured by $R-R$ interval variance, were detected between groups, regardless of the fact that the parasympathetic system seems to be the principal mediator of such a variability. This is in general accordance with previous findings in patients with major depression..$^{42}$

The occurrence of an increased sympathetic activity in the group of depressed patients was suggested by greater sympathetic skin response to standing and isometric exercise. Indeed, sympathetic skin response in humans is only affected by factors that modify the activity of cholinergic sympathetic postganglionic fibres to the skin. ${ }^{434}$ It should be noted, however, that the performance in tests known to evoke increased sympathetic outflow (namely, cold pressor, explosive sound, and mental arithmetic tests) or chemoreceptor mediated reflexes (hyperventilation) ${ }^{45}$ did not show significant differences between the groups. Moreover, changes in diastolic blood pressure after hand grip were similar in depressed patients and controls. Further studies are therefore necessary to evaluate the sympathetic tone in depressed patients. Interestingly, the same neurotransmitterthat is, acetylcholine-was implicated in the present study in two opposite abnormalities: a decreased parasympathetic, and an increased sympathetic activity. Thus the idea of a distorted single neurotransmitter function (for example, cholinergic hypersensitivity ${ }^{46}$ ) in major depression does not seem to be warranted by the foregoing results.

In summary, the results obtained support the conclusion that in major depression some tests show that autonomic function is altered, indicating a decreased parasympathetic activity, and presumably, increased sympathetic activity. These alterations may have implications for the increased risk of cardiac disease found in patients with major depression. ${ }^{235}$ 
These studies were supported in part by grants from the University of Buenos Aires and the Consejo Nacional de Investigaciones Cíentficas y Técnicas (CONICET) Argentina. SMG is a research fellow from CONICET.

1 Kraepelin E. Manic-depressive insanity and paranoia. Edinburgh: Livingstone, 1921:44-53.

2 Dreyfuss F, Dasberg H, Assael MI. The relationship of myocardial infarction to depressive illness. Psychother Psychosom 1969;17:73-81.

3 Dawson ME, Schell AM, Catania JJ. Autonomic correlates of depression and clinical improvement following electroconvulsive shock therapy. Psychophysiology 1977;14: 569-78.

4 Guinjoan SM, Bonanni Rey RA, Cardinali DP. Correlation between skin potential response and psychopathology in patients with affective disorders. pathology in patients with
Neuropsychobiology 1995;31:24-30.

5 Tsuang MT, Woolson KF, Flemming JA. Premature deaths in schizophrenia and affective disorders. An deaths in schizophrenia and affective disorders. An analysis of survival curves and variables affecting the
shortened survival. Arch Gen Psychiatry 1980;37:979-83.

6 Rabins PV, Harvis K, Koven S. High fatality rates of late life depression associated with cardiovascular disease. $\mathscr{f}$ Affect Disord 1985;9:165-7.

7 Kleiger RE, Miller JP, Bigger JT, Moss AJ. Decreased heart rate variability and its association with mortality after myocardial infarction. Am $\mathcal{f}$ Cardiol 1987;59. 252-6.

8 Myers GA, Martin GJ, Magid NM. Power spectral analysis of heart rate variability in sudden cardiac death: comparison to other methods. IEEE Trans Biomed Eng 1986;33: 1149-56.

9 Garrity TF, Klein RF. Emotional response and clinical severity as early determinants of six-month mortality

10 Mitchell PB, Bearn JA, Corn TH, Checkley SA. Growth hormone response to clonidine after recovery in patients with endogenous depression. Br $\mathcal{F}$ Psychiatry 1988;152: 34-8.

11 McLeod JG, Tuck RR. Disorders of the autonomic nervous system: Part 1. Pathophysiology and clinical features. Ann Neurol 1987;21:419-30.

12 Schondorf $R$. The role of the sympathetic skin response in the assessment of autonomic function. In: Low PA, ed Clinical Autonomic Disorders. Boston: Little, Brown and Co, 1993:231-41.

13 American Psychiatric Association. DSM-III-R: Diagnostic and statistical manual of mental disorders. 3rd ed revised. Washington DC: APA, 1987.

14 Medalia A, Scheinberg MD. Psychopathology in patients with Wilson's disease. Am $\mathcal{F}$ Psychiatry 1989;146:662-4.

15 Low PA, Zimmerman IR. Development of an autonomic laboratory. In: Low PA, ed. Clinical autonomic disorders. laboratory. In: Low PA, ed. Clinical autonomic

16 Low PA. Pitfalls in autonomic testing. In: Low PA, ed Clinical autonomic disorders. Boston: Little, Brown and Co, 1993:363.

17 Low PA, Pfeifer MA. Standardization of clinical tests for practice and clinical trials. In: Low PA, ed. Clinical autonomic disorders. Boston: Little, Brown and Co, 1993:294.

18 Sundkvist G, Almer L-O, Lilia B. Respiratory influence on heart rate in diabetes mellitus. $B M \mathcal{F}^{1979 ; 1: 924-5}$.

19 Levin AB. A simple test of cardiac function based upon the heart rate changes induced by the Valsalva manoeuvre. Am $\mathcal{F}$ Cardiol 1966;18:90-9.

20 Ewing DJ, Martyn CN, Young RJ, Clarke BF. The value of cardiovascular autonomic function tests: 10 years of cardiovascular autonomic function tests: 10 year

21 Ewing DJ, Irving JB, Kerr F. Cardiovascular responses to sustained handgrip in normal subjects and in patients with diabetes mellitus: a test of autonomic function. Clin Sci Mol Med 1974;46:295-306.

22 Hines EA, Brown GE. The cold pressor test for measuring the reactivity of the blood pressure: data concerning 571 normal and hypertensive subjects. Am Heart $\mathcal{f}$ 1936;11: $1-9$.
23 Ludbrook J, Vincent A, Walsh JA. Effects of mental arithmetic on arterial pressure and hand blood flow. Clin Exp Pharmacol Physiol suppl 1975;2:67-70.

24 Bennett T, Farquhar JK, Hosking DJ, Hampton JR. Assessment of methods for estimating autonomic nervous control of the heart in patients with diabetes mellitus. Diabetes 1978;27:1167-74.

25 Shahani BT, Halperin J, Boulu P, Cohen J. Sympathetic skin response - a method of assessing unmyelinated axon dysfunction in peripheral neuropathies. $\mathcal{F}$ Neurol Neurosurg Psychiatry 1984;47:536-42.

26 Gautschy B, Weidmann P, Gnadinger MP. Autonomic function tests as related to age and gender in normal man. Klinische Wochenschrift (Berlin) 1986;64:499-505.

27 Low PA, Walsh JC, Huang C-Y, MacLeod JG. The sympathetic nervous system in diabetic neuropathy-a clinical and pathological study. Brain 1975;98:341-56.

28 Ewing DJ, Campbell IW, Clarke BF. Assessment of cardiovascular effects in diabetic autonomic neuropathy and progen

29 Low PA, Neumann C, Dyck PJ, Fealey RD, Tuck RR. Evaluation of skin vasomotor reflexes by using lase Doppler velocimetry. Mayo Clin Proc 1983;58:583-92.

30 Duncan G, Johnson RH, Lambie DG, Whiteside EA. Evidence of vagal neuropathy in chronic alcoholics. Lancet 1980;ii: 1053-7.

31 Yeung Laiwah AAC, Mactier R, McColl KEL, Moore $\mathrm{MR}$, Goldberg A. Autonomic neuropathy in acute intermittent porphyria. 7 Neurol Neurosurg Psychiatry 1985; 48:1025-30.

32 Bannister R. Defective cardiovascular reflexes and supersensitivity to sympathomimetic drugs in autonomic failure. Brain 1979;102:163-76.

33 Niakan E, Harati Y. Sympathetic skin response in diabetic peripheral neuropathy. Muscle Nerve 1988;11:261-4.

34 Maselli RA, Jaspan JB, Soliven BC, Green AJ, Spire J-P, Arnason BGW. Comparison of sympathetic skin response with quantitative sudomotor axon reflex test in diabetic neuropathy. Muscle Nerve 1989;12:420-3.

35 Yokota T, Matsunaga T, Okiyama R, et al. Sympathetic skin response in patients with multiple sclerosis compared with patients with spinal cord transection and normal controls. Brain 1991;114:1381-94.

36 Dettmers C, Fatepour D, Faust H, Jerusalem F. Sympathetic skin response abnormalities in amyotrophic lateral sclerosis. Muscle Nerve 1993;16:930-4.

37 Sharpey-Schafer EP, Taylor DJ. Absent circulatory reflexes in diabetic neuritis. Lancet 1960;i:559-62.

38 Lake CR, Pickar D, Ziegler MG, Lipper S, Slater S, Murphy DL. High plasma norepinephrine levels in patients with major affective disorder. Am $\mathcal{F}$ Psychiatry patients with major

39 Lahmeyer HW, Bellier SN. Cardiac regulation and depression. F Psychiatr Res 1987;21:1-6.

40 Carney RM, Rich MW, teVelde A, Saini J, Clark K, Freedland KE. The relationship between heart rate, heart rate variability and depression in patients with coronary artery disease. $\mathcal{f}$ Psychosom Res 1988;32: 159-64.

41 Dalack GW, Roose SP. Perspectives on the relationship between cardiovascular disease and affective disorder. $f$ Clin Psychiatry 1990;51(suppl):4-9.

42 Yeragani VK, Pohl R, Balon R, Ramesh C, Glitz D, Jung I, Sherwood $P$. Heart rate variability in patients with major depression. Psychiatry Res 1991;37:35-46.

43 Hagbarth K-E, Hallin RG, Hongell A, Thorebjork HE, Wallin BG. General characteristics of sympathetic activity in human skin nerves. Acta Physiol Scand 1972;84: ity in hum.

44 Knezevic W, Bajada S. Peripheral autonomic surface potential: a quantitative technique for recording sympathetic conduction in man. $\mathcal{F}$ Neurol Sci 1985;67:239-51

45 Appenzeller $\mathrm{O}$. The autonomic nervous system. Amsterdam: Elsevier, 1990.

46 Janowsky DS, Risch SC. Cholinomimetic and anticholinergic drugs used to investigate an acetylcholine hypothesis of affective disorders and stress. Drug Development Research 1984;4:125-42. 